\title{
APLICAÇÃO DA EQUAÇÃO DE THOM PARA ESTIMATIVA DO CONFORTO TÉRMICO EM FUNÇÃO DAS VARIAÇÕES DE TEMPERATURA E UMIDADE RELATIVA DO AR NO BAIRRO CASTELO, BELO HORIZONTE-MG
}

\author{
Isabela Mara Lima ${ }^{(a)}$, Carlos Henrique Jardim ${ }^{(b)}$ \\ (a) Graduanda, Depto. de Geografia/Instituto de Geociências, UFMG, maraisabela.lima@gmail.com \\ (b) Docente, Depto. de Geografia/Instituto de Geociências, UFMG, cjardim@ yahoo.com
}

\section{Eixo: Climatologia em Diferentes Níveis Escalares: Mudanças e Variabilidades}

\begin{abstract}
Resumo
O presente artigo tem por objetivo avaliar as condições de conforto térmico no bairro Castelo, situado na Regional Pampulha, norte do município de Belo Horizonte - MG. Foram utilizados dados produzidos em campo durante o segmento temporal entre 11/09/2016 a 12/10/2016 e comparados com a estação meteorológica do INMET-Pampulha sediada na UFMG. A aplicação desses dados, mediante utilização do Índice de Temperatura Efetiva de Thom para avaliação do grau de conforto térmico indicou apenas situações horárias favoráveis ao conforto, havendo necessidade de incluir novas situações diárias.
\end{abstract}

Palavras chave: temperatura do ar; umidade relativa; conforto térmico; clima urbano.

\section{Introdução}

$\mathrm{Na}$ atualidade há grande preocupação ao redor das alterações no meio ambiente, induzidas pela ação antrópica. Estudos realizados pela comunidade científica nos últimos anos vêm alertando a sociedade que essas alterações podem resultar em efeitos nas mais diversas dimensões. Assis (2010) ressalta, por exemplo, as perturbações nos mecanismos de troca de calor entre superfície e atmosfera, que provocam desequilíbrios na dinâmica do ar e consequentemente nas características do clima, tanto em nível local como em outras escalas. A preocupação não se restringe apenas ao meio ambiente, mas também à qualidade de vida do ser humano em um meio propício ao seu desenvolvimento e bem-estar.

No âmbito da climatologia, em especial o clima urbano, há estudos que abordam a temática do conforto térmico, realizados visando bem estar humano. De acordo com Kulka (2010), o ambiente térmico engloba um conjunto de diversas variáveis térmicas, que influenciam de forma direta ou indireta no organismo do indivíduo, alterando no seu bem-estar de forma positiva ou negativa. Monteio (1976) ainda afirma que o conforto engloba componentes termodinâmicos que interferem diretamente na comodidade e saúde do ser humano, e, principalmente, atuando como um bom filtro perceptivo de cada indivíduo. 
Há muitos estudos realizados para promover maior qualidade de vida aos humanos, em especial em ambientes fechados (por meio de ventilação, exaustores e aquecedores). Todavia, o bem-estar também abrange espaços abertos como vias públicas, praças e parques. Para isso, diversos índices e equações foram desenvolvidos como retratam Alucci \& Monteiro (2007), que reúnem diversos modelos específicos para ambientes livres, existentes para as mais diversas condições físicas e de acesso a equipamentos. $\mathrm{O}$ princípio básico para a análise do conforto térmico abrange diversas variáveis térmicas, que podem ser divididas em duas categorias: (1) aspectos físicos como insolação, latitude, estações do ano, umidade, vento e nebulosidade e (2) aspectos do próprio indivíduo, que abrangem suas características físicas (peso, idade, altura, gênero, vestimenta, cultura do local em que ele reside etc.).

No presente artigo, trabalharam-se apenas com variáveis relacionadas à primeira categoria a partir de mensurações horárias por meio de registradores data logger, durante o período de 11/09/2016 a 12/10/2016, com a finalidade de avaliar as condições térmicas através de índices de conforto para dois postos de mensuração escolhidos. Dessa forma, considerando esta apresentação, o objetivo deste artigo é investigar as relações entre tipo de tempo e variação da temperatura e umidade relativa do ar em ambiente urbano, visando verificar as condições de conforto térmico e higrométrico do ar.

\section{Procedimentos metodológicos}

Os procedimentos metodológicos adotados englobaram três etapas: (1) a realização de uma revisão bibliográfica, (2) delimitação da área de estudo; escolheu-se o bairro Castelo por ser relativamente novo na capital e de forte crescimento imobiliário (composto por altas edificações) e (3) instalação dos sensores automáticos do tipo datalogger de mensuração horária. O posto 1 possui coordenadas $19^{\circ} 52^{\prime} 33.32$ ”S e $43^{\circ} 59^{\prime} 42.04^{\prime \prime} \mathrm{W}, 849 \mathrm{~m}$ de altitude e o posto 2 tem coordenadas $19^{\circ} 52^{\prime} 54.1^{\prime \prime} \mathrm{S}$ e $44^{\circ} 00^{\prime} 06.8^{\prime}$ 'W, $845 \mathrm{~m}$ de elevação. Ambos os postos situam-se em uma área residencial (figura 1).

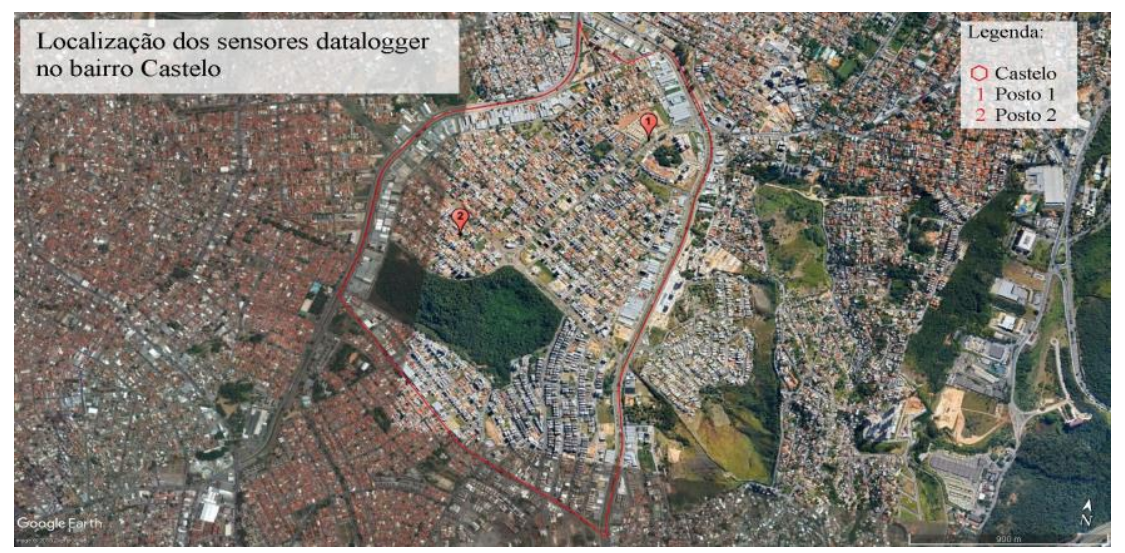

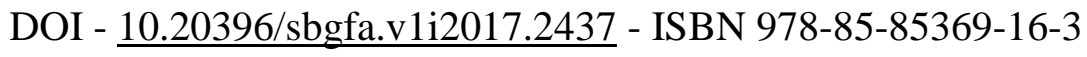




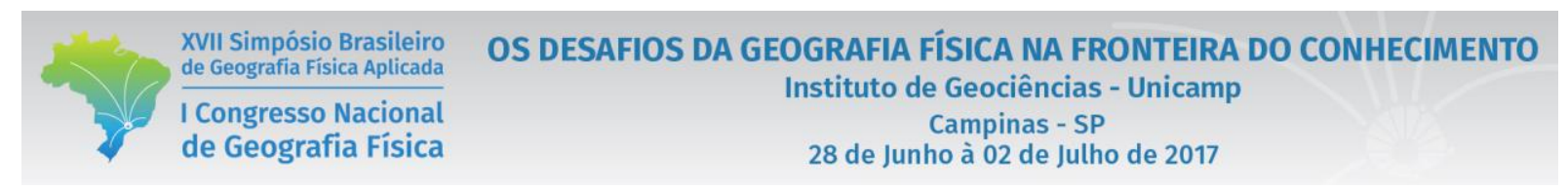

Figura 1 - Localização da área de estudo. Fontes: Google Earth (2017). Organização: Isabela M. Lima.

Após o tempo de mensuração, os dados foram coletados, tabulados e comparados para fins de controle com aqueles provenientes da estação meteorológica do INMET-Pampulha, localizada na Estação Ecológica da Universidade Federal de Minas Gerais. Em seguida foram escolhidos dois dias de condições atmosféricas distintas dentro do período analisado, com a finalidade de apontar diferentes condições de (des)conforto térmico. A equação escolhida buscou satisfazer às condições de mensuração dos dados em ambientes abertos e a disponibilidade de equipamentos utilizados nesta pesquisa. Alucci \& Monteiro (2007) reunem em um artigo mais de vinte modelos de índices de conforto térmico, especificamente para ambientes abertos. Em função disso e de já ter sido testado em outro trabalho de natureza semelhante (CORDEIRO e LIMA, 2016) foi escolhido o Índice de Temperatura Efetiva de Thom (1959), calculado a partir da equação $\mathrm{TE}=0,4(\mathrm{Td}+\mathrm{Tw})+4,8$. Em que $\mathrm{Td}$ equivale à temperatura de bulbo seco e $\mathrm{Tw}$ corresponde à temperatura do bulbo úmido (ambas dadas em ${ }^{\circ} \mathrm{C}$ ). Tendo isto em vista, foram utilizados os dados de temperatura e umidade relativa instantânea.

Os resultados obtidos após os cálculos da fórmula de Temperatura Efetiva (TE) foram interpretados de acordo com uma tabela de classificação de temperatura efetiva (Tabela 1).

Tabela 1 - Classificação de temperatura efetiva em função do vento, de acordo com Laboratório de Meteorologia Aplicada a Sistemas de Tempo Regionais - MASTER - IAG/USP.

\begin{tabular}{l|l|l|l|l|l}
\hline $\mathrm{TE}\left({ }^{\circ} \mathrm{C}\right)$ & Sensação térmica & Grau de estresse fisiológico & $\mathrm{TE}\left({ }^{\circ} \mathrm{C}\right)$ & Sensação térmica & Grau de estresse fisiológico \\
\hline$<5$ & Muito frio & Extremo estresse ao frio & $22-25$ & Confortável & Neutralidade térmica \\
\hline $\mathbf{5 - 1 0}$ & Frio & Extremo estresse ao frio & $25-28$ & Ligeiramente quente & Ligeiro suor; vasodilatação \\
\hline $10-13$ & Moderadamente frio & Tiritar & $28-31$ & Quente moderado & Suando \\
\hline $13-16$ & Ligeiramente frio & Resfriamento do corpo & $31-34$ & Quente & Suor em profusão \\
\hline $16-19$ & Pouco frio & Ligeiro resfriamento do corpo & $>34$ & Muito quente & Falha na termoregulação \\
\hline $19-22$ & Ligeiramente fresco & Vasoconstrição & & & \\
\hline
\end{tabular}

Fonte: Adaptado de MASTER - IAG/USP (2009). Organização: Isabela M. Lima

Por fim, depois de realizadas estas etapas, foram examinadas imagens de satélite e cartas sinóticas (disponíveis nos endereços eletrônicos <www.cptec.inpe.br> e <www.mar.mil.br>) a fim de analisar e caracterizar a influência das condições atmosféricas do segmento temporal em questão para os dias selecionados para análise.

\section{Resultados}

Durante o período da coleta de dados, as condições atmosféricas foram predominantemente de tempo estável na maior parte dos dias, em que as condições atmosféricas se alternaram entre a ação do ASAS (Alta Subtropical do Atlântico Sul) e a ação da MPAt (Massa Polar Atlântica tropicalizada ou em vias de DOI - 10.20396/sbgfa.v1i2017.2437 - ISBN 978-85-85369-16-3 


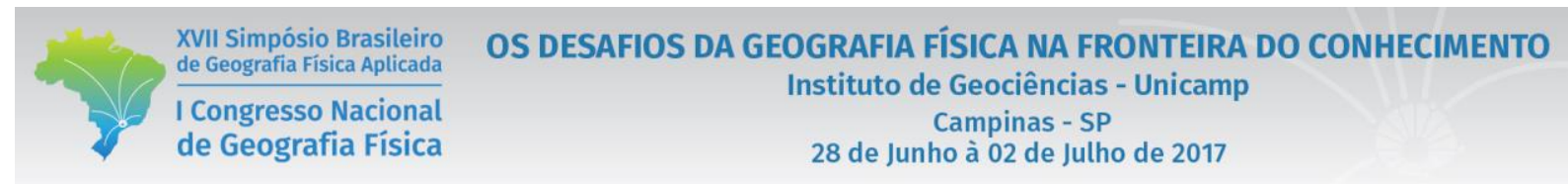

tropicalização). As situações de desequilíbrio se deram próximas ao início do mês de outubro, em que as condições atmosféricas foram marcadas pela ação de uma linha de instabilidade presente no estado de Minas Gerais, migrando para norte do país nos dias seguintes.

A primeira data escolhida foi o dia 13/09/2016, dia em que prevaleceram as condições de estabilidade devido à ação da MPA tropicalizada. Este dia representou um dos menores índices de conforto térmico, como observado na figura 2. Apesar disso, não se enquadra na condição de tempo de conforto térmico (Tabela 1), uma vez que as temperaturas ultrapassaram o intervalo de $22^{\circ} \mathrm{C} \mathrm{a} 25^{\circ} \mathrm{C}$, salvo o horário de $18 \mathrm{~h}$ para os sensores instalados no bairro Castelo. As condições térmicas para este dia variaram de ligeiramente quente a muito quente, caracterizando leve desconforto térmico, apesar de apresentar um dos dias de menores índices de acordo os cálculos da equação de Thom.

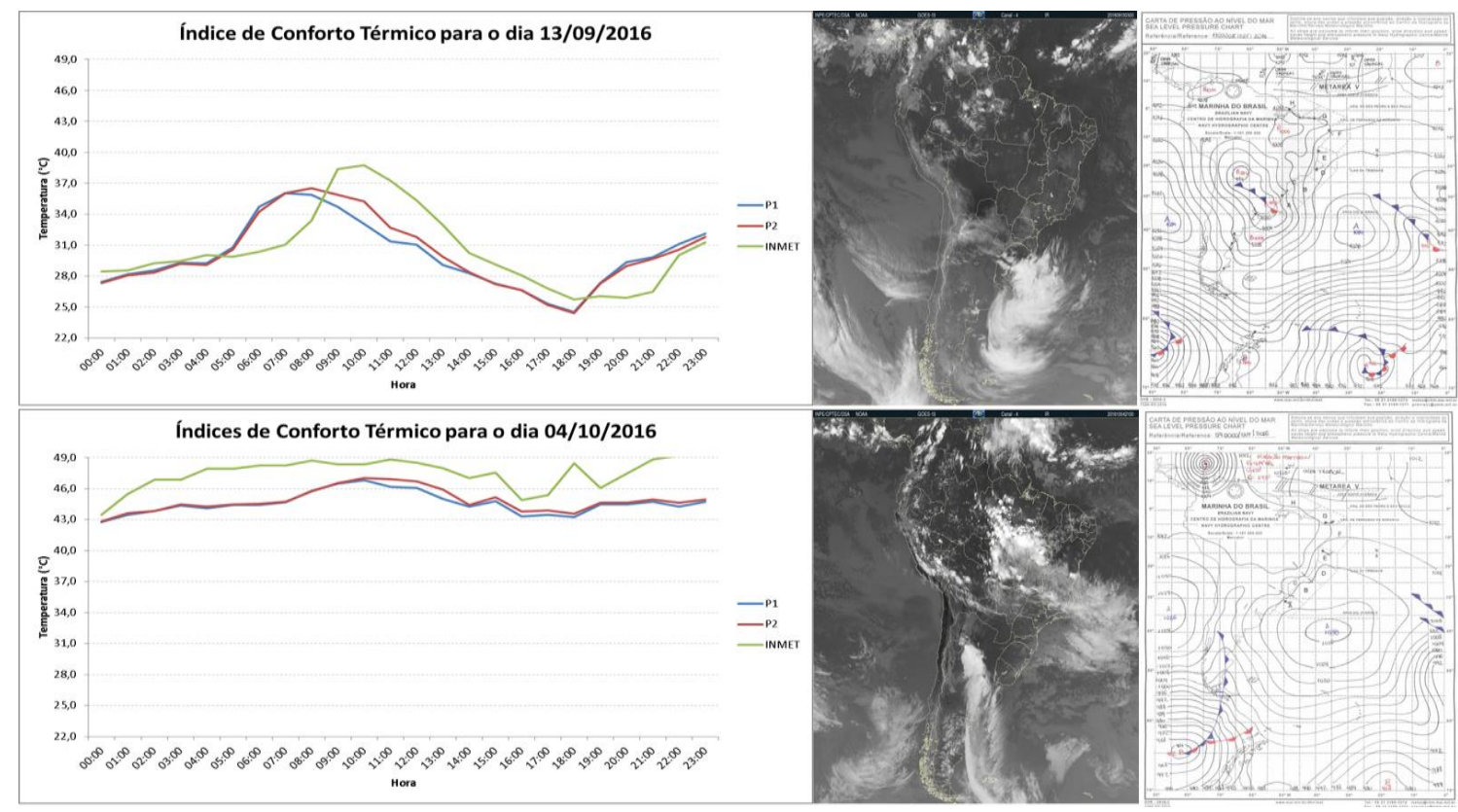

Figura 2 - Condições térmicas para os dias 13/09 e 04/10/2016. Organização: Isabela M. Lima.

Foi verificado que os índices correspondentes ao de conforto térmico (variando entre os $22^{\circ} \mathrm{C}$ e $25^{\circ} \mathrm{C}$ ) foram observados apenas em dias pontuais da seção temporal de mensuração (dias 13/09/2016, 14/09/2016 e 08/10/2016), e especificamente no período de final da tarde e início da noite.

O dia que apresentou altos índices de temperatura efetiva foi o dia 04/10/2016, devido à presença de uma linha de instabilidade (figura 2). Foram observados altos valores de umidade relativa do ar e temperaturas constantes ao longo de todo dia, em que apresentou uma média diária de aproximadamente $18,5{ }^{\circ} \mathrm{C}$ para os três postos. Estes fatores claramente contribuíram para um estresse térmico, como demonstra a figura 2, 


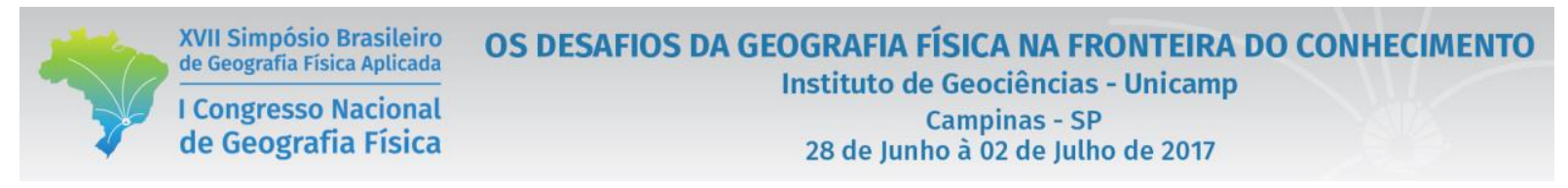

em que o desconforto foi atuante durante todo o dia, ultrapassando a última classificação do laboratório da MASTER/USP (Tabela 1). De acordo com esta classificação, índices a partir de $34^{\circ} \mathrm{C}$, já apresentam falha na termoregulação do organismo e sensação de muito quente, indicando elevado estresse térmico.

\section{Considerações Finais}

Como se trata de pesquisa em andamento, haverá necessidade de reavaliar, inclusive, aspectos da metodologia empregada. O dia 04/10/2016, por exemplo, apresentou temperaturas relativamente baixas, porém altas taxas de umidade. Isso fez com que o valor do índice ficasse alto e classificado erroneamente como "muito quente". Essa situação pode ser interpretada como uma necessidade de rever a equação aplicada, ou não, uma vez que altas taxas de umidade do ar (independente da temperatura) induzem à sensação de desconforto, já que inibe a transpiração humana, um dos principais mecanismos de termoregulação.

\section{Bibliografia}

ALUCCI, M. P.; MONTEIRO, L. M. Questões teóricas de conforto térmico em espaços abertos: consideração histórica, discussão do estado da arte e proposição de classificação de modelos. Associação Nacional de Tecnologia do Ambiente Construído, Porto Alegre, v. 7, n. 3, p. 43-58, jul./set. 2007.

ASSIS, W. L. O sistema clima urbano do município de Belo Horizonte na perspectiva têmporo-espacial. UFMG, Belo Horizonte, 2010. 319 p. Tese (Doutorado em geografia)-Universidade Federal de Minas Gerais, Instituto de Geociências, Departamento de Geografia, 2010.

CORDEIRO, B. H; LIMA, I. M. Microclimas e (des)conforto térmico nas praças da regional Pampulha, em Belo Horizonte/MG. In: XII Simpósio Brasileiro de Climatologia Geográfica. Variabilidade e Suscetibilidade Climática: Implicações Ecossistêmicas e Sociais, 20116, Goiânia. Anais... Goiânia: UFG, 2016.

INSTITUTO NA CIONAL DE PESQUISAS ESPACIAIS. Divisão de Satélites e Sistemas Ambientais - Banco de Dados de Imagens. Disponível em: <http://satelite.cptec.inpe.br/acervo/goes.formulario.logic;jsessionid=0870CBF0FC92A8597B73CC24397819BB >. Acesso em: 22 de outubro de 2016.

KULKA, Daniele Duarte. Conforto térmico em áreas verdes urbanas no município de Itapetinga, BA. UESB, Itapetinga, 2014, 71p. Dissertação (Mestrado em Ciências Ambientais)-Universidade Estadual do Sudoeste da BA, 2010.

MARINHA DO BRASIL. Diretoria de Hidrografia e Navegação - Centro de Hidrografia da Marinha - Serviço Meteorológico Marinho - $\quad$ Cartas Sinóticas. Disponível em: <https://www.mar.mil.br/dhn/chm/meteo/prev/cartas/cartas.htm>. Acesso em: 22 de outubro de 2016.

MONTEIRO, C.A.F. Teoria e clima urbano. São Paulo: IG06-USP, 1976. (Série Teses e Monografias n. 25). 